\title{
Chitosan-Coated Octadecyl-Functionalized Magnetite Nanoparticles: Preparation and Application in Extraction of Trace Pollutants from Environmental Water Samples
}

\author{
Xiaole Zhang, ${ }^{\text {t, }}$ Hongyun Niu, ${ }^{\dagger}$ Yuanyuan Pan, ${ }^{\dagger}$ Yali Shi, ${ }^{\dagger}$ and Yaqi Cai ${ }^{*, t}$ \\ The State Key Laboratory of Environmental Chemistry and Ecotoxicology of the Research Center for \\ Eco-Environmental Sciences, Chinese Academy of Sciences, Beijing 100085, and College of Chemical Engineering \\ and Biological Technology, Hebei Polytechnic University, Tangshan, Hebei 063000, China
}

In the present study, chitosan-coated octadecyl-functionalized magnetite nanoparticles $\left(\mathrm{Fe}_{3} \mathrm{O}_{4}-\mathrm{C}_{18}-\right.$ chitosan MNPs) are synthesized and used as an adsorbent to extract trace analytes from environmental water samples. The magnetic nanoparticles, $20 \mathrm{~nm}$ in diameter, are of uniform size and have a high magnetic saturation value of $52 \mathrm{emu} \mathrm{g}^{-1}$, which endue the adsorbent with a large surface area and convenience of isolation. The anionic pollutants, perfluorinated compounds (PFCs), are trapped by the octadecyl group of the interior hydrophobic layer. The positively charged chitosan polymer coating also contributes to PFC enrichment. At the same time, the coating improves the dispersibility of MNPs in aqueous solution and enhances the anti-interference ability of the adsorbent to natural organic macromolecules in complex samples by size exclusion or electrostatic repulsion. A liquid chromatography-tandem mass spectrometry system is employed in the determination of PFCs after preconcentration with the MNP adsorbent. The predominant factors affecting preconcentration are investigated and optimized. Under the selected conditions, concentration factors of 1000 are achieved by extracting the analytes from $500 \mathrm{~mL}$ of several environmental water samples and concentrating the eluants to $0.5 \mathrm{~mL}$ with a nitrogen flow. The method detection limits obtained for perfluorooctanoic acid (PFOA), perfluorooctanesulfonic acid (PFOS), perfluorononanoic acid (PFNA), perluorodecanoic acid (PFDA), perfluoroundecanoic acid (PFUnDA), perfluorododecanoic acid (PFDoDA), and perfluorotetradecanoic acid (PFTA) in Gaobeidian wastewater are $0.24,0.093,0.24,0.14,0.075,0.24$, and $0.17 \mathrm{ng} \mathrm{L}^{-1}$, respectively. Recoveries of PFOA, PFOS, PFNA, PFDA, PFUnDA, PFDoDA, and PFTA are in the ranges of $88-108 \%, 63-112 \%, 79-109 \%$, $56-107 \%, 66-106 \%, 56-106 \%$, and $66-103 \%$ for four spiked water samples with low relative standard deviation $(2-8 \%)$, which indicates good method precision. The advantages of this novel adsorbent are high extraction efficiency, anti-interference, and convenient operation.
In the past decade, magnetic nanocomposite materials have attracted much attention in various scientific fields such as biotechnology, biomedicine, and environmental and material science $^{1-4}$ for their unique size and superparamagnetic property. Magnetic nanoparticles (MNPs), such as magnetite $\left(\mathrm{Fe}_{3} \mathrm{O}_{4}\right)$ and maghemite $\left(\gamma-\mathrm{Fe}_{2} \mathrm{O}_{3}\right)$, have been modified with metal, metal oxide, an organic molecule, a polymer, and even a biomacromolecule for different purposes. ${ }^{5-9}$ Recently, there has been an increasing interest in magnetic nanoparticle adsorbents for the preconcentration of target analytes from environmental or biological samples. Several groups, including ours, have synthesized various MNPs with special functional ligands bound onto the surface and applied them to the extraction of different analytes from water samples. ${ }^{10-17}$ These MNP adsorbents, with large surface area and extraction capacity, can be quickly isolated from matrix solutions by a magnet after adsorption of analytes because

* To whom correspondence should be addressed. E-mail: caiyaqi@rcees.ac.cn. Phone: (086) 010-62849239. Fax: (086) 010-62849182.

$\dagger$ Chinese Academy of Sciences.

Hebei Polytechnic University.

(1) Liu, J. C.; Tsai, P. J.; Lee, Y. C.; Chen, Y. C. Anal. Chem. 2008, 80, 54255432.

(2) Sun, Y. K.; Duan, L.; Guo, Z. R.; DuanMu, Y.; Ma, M.; Xu, L. N.; Zhang, Y.; Gu, N. J. Magn. Magn. Mater. 2005, 285, 65-70.

(3) Liu, J. F.; Zhao, Z. S.; Jiang, G. B. Environ. Sci. Technol. 2008, 42, 69496954.

(4) Latham, A. H.; Williams, M. E. Acc. Chem. Res. 2008, 41, 411-420.

(5) Mandal, M.; Kundu, S.; Ghosh, S. K.; Panigrahi, S.; Sau, T. K.; Yusuf, S. M.; Pal, T. J. Colloid Interface Sci. 2005, 286, 187-194.

(6) Zhu, Y. F.; Kockrick, E.; Ikoma, T.; Hanagata, N.; Kaskel, S. Chem. Mater. 2009, 21, 2547-2553.

(7) Ji, Y. S.; Liu, X. Y.; Guan, M.; Zhao, C. D.; Huang, H. Y.; Zhang, H. X.; Wang, C. M. J. Sep. Sci. 2009, 32, 2139-2145.

(8) Käppler, T. E.; Hickstein, B.; Peuker, U. A.; Posten, C. J. Biosci. Bioeng. 2008, 105, 579-585.

(9) Lin, P. C.; Tseng, M. C.; Su, A. K.; Chen, Y. J.; Lin, C. C. Anal. Chem. 2007, 79, 3401-3408.

(10) Safarikova, M.; Safarik, I. Eur. Cells Mater. 2002, 3 (Suppl. 2), 192195.

(11) Liu, Y. L.; Jia, L. Microchem. J. 2008, 89, 72-76.

(12) Suleiman, J. S.; Hu, B.; Peng, H. Y.; Huang, C. Z. Talanta 2009, 77, 15791583.

(13) Zargar, B.; Parham, H.; Hatamie, A. Talanta 2009, 77, 1328-1331.

(14) Zhao, X. L.; Shi, Y. L.; Wang, T.; Cai, Y. Q.; Jiang, G. B. J. Chromatogr., A 2008, 1188, 140-147.

(15) Zhao, X. L.; Cai, Y. Q.; Wang, T.; Shi, Y. L.; Jiang, G. B. Anal. Chem. 2008, 80, 9091-9096.

(16) Liu, Y.; Li, H. F.; Lin, J. M. Talanta 2009, 77, 1037-1042.

(17) Sha, Y. F.; Deng, C. H.; Liu, B. Z. J. Chromatogr., A 2008, 1198, 27-33. 
of their superparamagnetism. Thus, target compounds are extracted rapidly from large-volume samples, and the difficulties of solid-liquid separation or the high back-pressure when passing through the solid-phase extraction (SPE) column are avoided. However, the active functional groups which are exposed directly into the water solution tend to be contaminated by the natural organic matter (NOM) in complex matrixes and lose their adsorption abilities. Moreover, the MNPs of sub-50 nm with a hydrophobic surface are difficult to disperse in water samples. These can limit the application of functionalized MNP adsorbents in extraction of targets from large-volume water samples. A layer of porous hydrophilic polymer coating on the surface of this kind of MNPs may solve these problems, and the pore size of the coating is appropriate to hold back the macromolecules of NOM without influencing the adsorption of analytes.

Chitosan, an N-deacetylated derivative of chitin, may be a good candidate. Chitosan is a linear polyglucosamine with a 1,4-linkage. In its skeleton, there are plenty of reactive amino and hydroxyl groups, which can be easily cross-linked with covalent or ionic cross-linkers to form chitosan hydrogel. The most common covalent cross-linker is glutaraldehyde, which has been used by many groups to cross-link chitosan on the surface of MNPs for immobilization of enzymes or removal of heavy metal. ${ }^{18-22}$ However, the covalent cross-linking of chitosan is performed in liquid paraffin through a microemulsion procedure, which is complicated and time-consuming. Furthermore, the toxic reagents would be introduced into the hydrogel through covalent crosslinking. The amino groups of glucosamine are protonated at $\mathrm{pH}$ $<6.5^{22}$ and possess a high density of positive charge, which endues chitosan with the reactivity with negatively charged chemicals (e.g., alginate, citrate, and tripolyphosphate, etc.) to form a network structure through ionic bridges between polyglucosamine chains. ${ }^{23-25}$ Among them, tripolyphosphate is the most commonly used cross-linker to prepare ionic cross-linking chitosan polymer. The size of the pore and cross-linking degree in the polymer can be regulated by changing the ratio of chitosan and tripolyphosphate, and the method is proved to be simple, mild, and fast.

In this work, we reported the preparation of chitosan-coated octadecylfunctionalized magnetite nanoparticles $\left(\mathrm{Fe}_{3} \mathrm{O}_{4}-\mathrm{C}_{18}-\right.$ chitosan MNPs) and its potential application in the preconcentration of analytes from environmental water samples. Magnetite nanoparticles were modified with an octadecyl group by silylation reaction. Then, the surface of the obtained $\mathrm{Fe}_{3} \mathrm{O}_{4}-\mathrm{C}_{18}$ MNPs were coated with a layer of hydrophilic chitosan-tripolyphosphate polymer by ionotropic gelation to form a novel type

(18) Li, G. Y.; Jiang, Y. R.; Huang, K. L.; Ding, P.; Yao, L. L. Colloids Surf., A. 2008, 320, 11-18.

(19) Jiang, D. S.; Long, S. Y.; Huang, J.; Xiao, H. Y.; Zhou, J. Y. Biochem. Eng. J. 2005, 25, 15-23.

(20) Peniche, H.; Osorio, A.; Acosta, N.; Campa, A.; Peniche, C. J. Appl. Polym. Sci. 2005, 98, 651-657.

(21) Liu, X. W.; Hu, Q. Y.; Fang, Z.; Zhang, X. J.; Zhang, B. B. Langmuir 2009 , $25,3-8$.

(22) Lei, Z. L.; Pang, X. L.; Li, N.; Lin, L.; Li, Y. L. J. Mater. Process. Technol. 2008, 209, 3218-3225.

(23) Ma, W.; Ya, F. Q.; Han, M.; Wang, R. J. Hazard. Mater. 2007, 143, 296302.

(24) Zhu, L. Z.; Ma, J. W.; Jia, N. Q.; Zhao, Y.; Shen, H. B. Colloids Surf., B 2009, 68, 1-6.

(25) Kyzas, G. Z.; Bikiaris, D. N.; Lazaridis, N. K. Langmuir 2008, 24, 47914799. of $\mathrm{Fe}_{3} \mathrm{O}_{4}-\mathrm{C}_{18}$-chitosan MNP adsorbent with an interior hydrophobic octadecyl group and exterior hydrophilic chitosan polymer coating. Fluorinated compounds (PFCs), a group of widely used anionic surfactants, were selected as target analytes because of their persistence in the environment, ${ }^{26}$ bioaccumulation in animals, ${ }^{27}$ biomagnification in higher organisms through the food web, ${ }^{28}$ and immunological and neurological toxicity. ${ }^{29}$ Determination of PFCs was conducted on a liquid chromatography - tandem mass spectrometry system (HPLCMS/MS) after preconcentration with the MNP adsorbent. The predominant factors affecting the extraction were investigated and optimized. The influences of humic acid and protein on the adsorption of PFCs were also studied. Compared with the conventional SPE adsorbents, the obtained material has a large surface area because of its nanoscaled size and exhibits a high extraction efficiency to anionic organic pollutants due to the dual functions of the interior octadecyl groups and the exterior positively charged chitosan polymer. In addition, the superparamagnetic $\mathrm{Fe}_{3} \mathrm{O}_{4}$ core contributes to the rapid separation of adsorbent from the matrix solution, while a long operating time is required when a large volume of water sample passes through the SPE column. Moreover, the porosity and basketlike structure of the chitosan-tripolyphosphate polymer also improves the dispersibility of adsorbent in aqueous solution and prevents the macromolecules such as NOM in complex matrixes from entering the interior hydrophobic layer, but allows the small molecules of analytes to pass through readily. Thus, contamination of adsorbent by NOM in complex samples is avoided, and extraction of target compounds directly from complex environmental samples is achieved. To the best of our knowledge, this is the first report that $\mathrm{Fe}_{3} \mathrm{O}_{4}-\mathrm{C}_{18}$-chitosan MNPs are synthesized and used for extraction of trace analytes from large-volume water samples.

\section{EXPERIMENTAL SECTION}

Chemicals and Materials. Perfluorooctanoic acid (PFOA), perfluorononanoic acid (PFNA), perfluorodecanoic acid (PFDA), perfluoroundecanoic acid (PFUnDA), perfluorododecanoic acid (PFDoDA), and perfluorotetradecanoic acid (PFTA) were obtained from Alfa Aesar (Ward Hill, MA); perfluorooctanesulfonic acid (PFOS) was purchased from Sigma-Aldrich (St. Louis, MO). Standard stock solutions $\left(50 \mu \mathrm{g} \mathrm{L}^{-1}\right)$ containing these compounds were prepared in methanol and stored at $4{ }^{\circ} \mathrm{C}$. Working solutions were prepared daily by appropriate dilution of the stock solutions with methanol. LC-grade methanol and acetonitrile were supplied by Merck (Darmstadt, Hessen, Germany). Octadecyltriethoxysilane was obtained from Tokyo Chemical Industry Co. Ltd. (Tokyo, Japan). Chitosan (MW $4.9 \times 10^{5}$, degree of deacetylation 95\%) was from Dalian Xindie Chitin Co. (Dalian, Liaoning, China). Sodium tripolyphosphate and humic acid were obtained from Sigma-Aldrich. Bovine serum albumin (BSA) was from Beijing Xinjingke Biotechnology Co.

(26) Goss, K. U. Environ. Sci. Technol. 2008, 42, 456-458.

(27) Guruge, K. S.; Manage, P. M.; Yamanaka, N.; Miyazaki, S.; Taniyasu, S.; Yamashita, N. Chemosphere 2008, 73, S210-S215.

(28) Li, X. M.; Yeung, L. W. Y.; Taniyasu, S.; Li, M.; Zhang, H. X.; Liu, D.; Lam, P. K. S.; Yamashita, N.; Dai, J. Y. Environ. Sci. Technol. 2008, 42, 70787083.

(29) Johansson, N.; Fredriksson, A.; Eriksson, P. Neurotoxicology 2008, 29, 160169. 


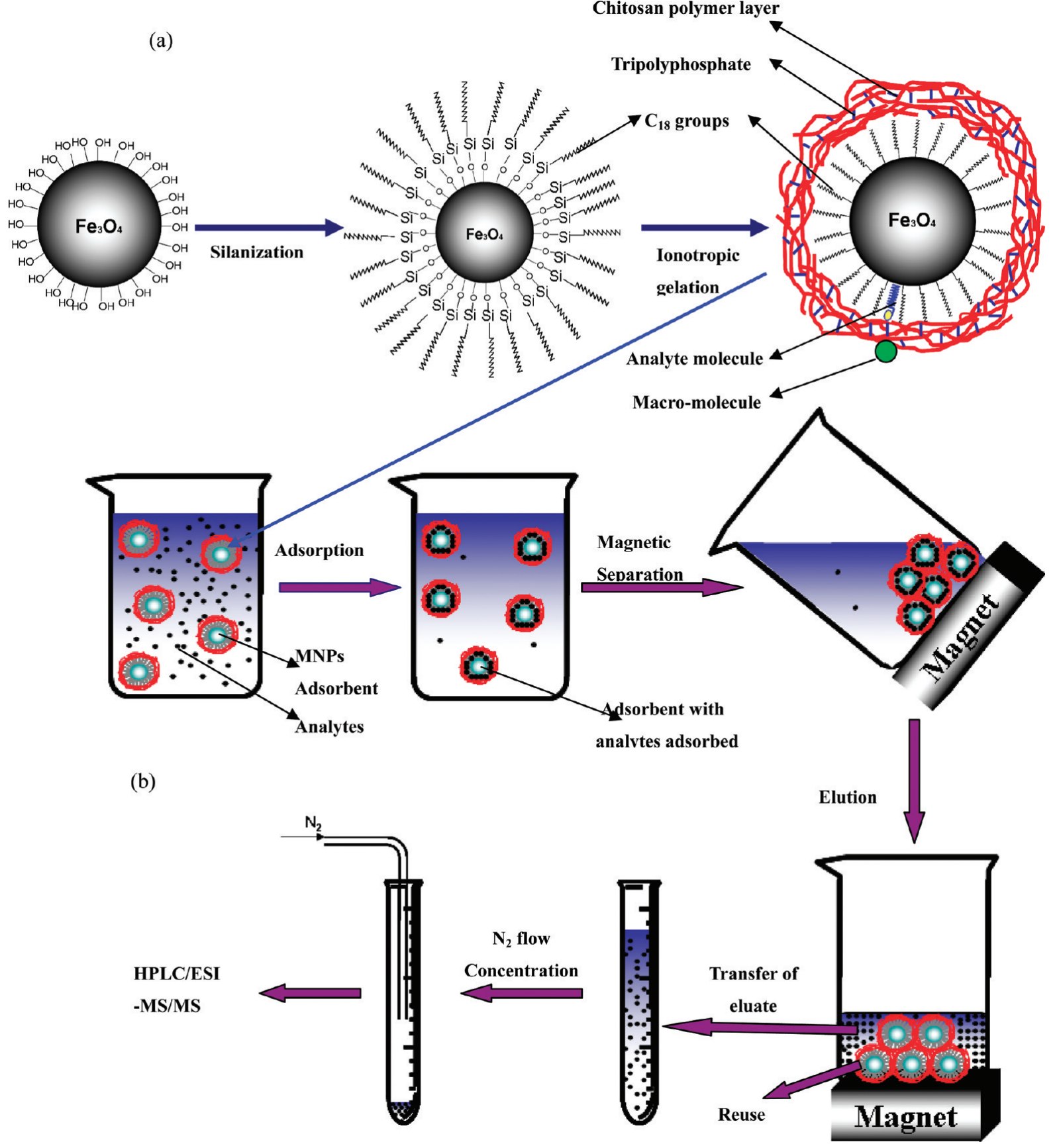

Ltd. (Beijing, China). $\mathrm{FeCl}_{3} \cdot 6 \mathrm{H}_{2} \mathrm{O}, \mathrm{FeCl}_{2} \cdot 4 \mathrm{H}_{2} \mathrm{O}$, toluene, ethanol, sodium hydroxide, and hydrochloric acid were guaranteegrade reagents from Beijing Chemicals Co. Ltd. (Beijing, China). All reagents were used without further purification. Ultrapure water was prepared in the laboratory using a Milli-Q SP reagent water system from Millipore (Milford, MA).

Preparation of $\mathrm{Fe}_{3} \mathrm{O}_{4}-\mathrm{C}_{18}-$ Chitosan MNPs. The process of preparation of $\mathrm{Fe}_{3} \mathrm{O}_{4}-\mathrm{C}_{18}$-chitosan MNPs is illustrated in Scheme 1a. First, $\mathrm{Fe}_{3} \mathrm{O}_{4}$ MNPs were synthesized by the wellknown coprecipitation method ${ }^{14}$ and vacuum-dried at $50^{\circ} \mathrm{C}$ for $24 \mathrm{~h}$ after being washed with $200 \mathrm{~mL}$ of deionized water four times. Second, the $\mathrm{Fe}_{3} \mathrm{O}_{4}$ MNPs were functionalized with octadecyltriethoxysilane according to the previously reported method $^{11}$ with a minor modification. Briefly, $1.2 \mathrm{~g}$ of dried
$\mathrm{Fe}_{3} \mathrm{O}_{4}$ MNPs was dispersed in $60 \mathrm{~mL}$ of anhydrous toluene with ultrasonication, followed by adding $0.6 \mathrm{~mL}$ of octadecyltriethoxysilane under vigorous stirring. The mixtures were then put into sealed autoclaves and heated at $120{ }^{\circ} \mathrm{C}$ for $6 \mathrm{~h}$ in a furnace. The $\mathrm{Fe}_{3} \mathrm{O}_{4}-\mathrm{C}_{18}$ MNPs were obtained after being washed with anhydrous ethanol and drying. Third, chitosantripolyphosphate polymer was coated on the $\mathrm{Fe}_{3} \mathrm{O}_{4}-\mathrm{C}_{18} \mathrm{MNPs}$ through ionotropic gelation: ${ }^{25}$ An $0.8 \mathrm{~g}$ portion of as-prepared $\mathrm{Fe}_{3} \mathrm{O}_{4}-\mathrm{C}_{18}$ MNPs was dispersed in $30 \mathrm{~mL}$ of chitosan solution (4 $\mathrm{mg} \mathrm{mL}^{-1}$, dissolved in $2 \%$ acetic acid). The suspension was mixed by ultrasonic irradiation for $30 \mathrm{~min}$, and then $15 \mathrm{~mL}$ of sodium tripolyphosphate solution $\left(0.5 \mathrm{mg} \mathrm{mL} \mathrm{mL}^{-1}\right)$ was added dropwise under vigorous mechanical stirring and aged for 30 min. The $\mathrm{Fe}_{3} \mathrm{O}_{4}-\mathrm{C}_{18}-$ chitosan MNPs were recovered from the 

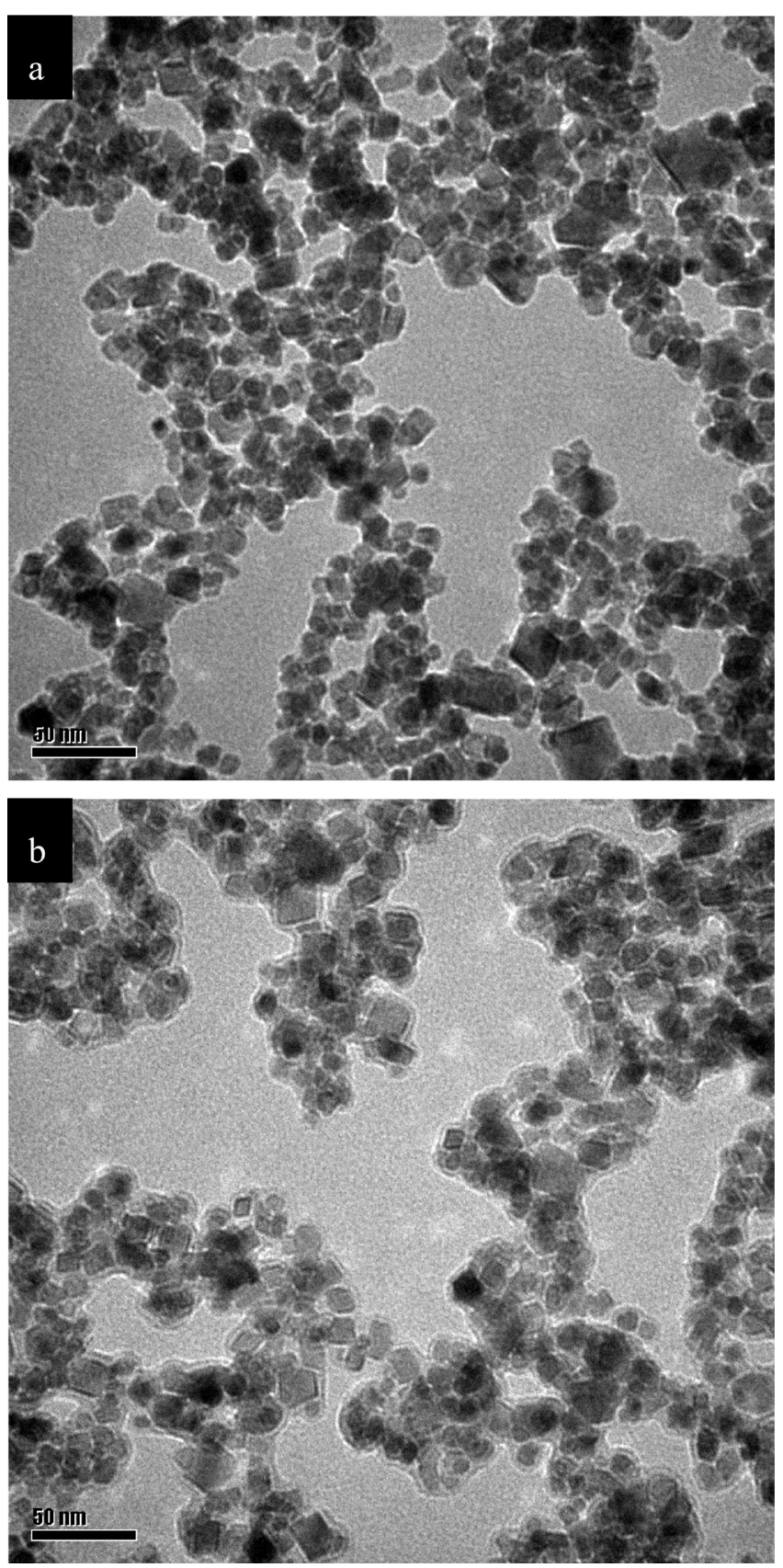

Figure 1. TEM images of $\mathrm{Fe}_{3} \mathrm{O}_{4} \mathrm{MNPs}(\mathrm{a})$ and $\mathrm{Fe}_{3} \mathrm{O}_{4}-\mathrm{C}_{18}$-chitosan MNPs (b).

reaction mixture by a magnet, washed several times with water and ethanol, and dried at $50{ }^{\circ} \mathrm{C}$ in a vacuum oven for $24 \mathrm{~h}$.

Characterizations of $\mathrm{Fe}_{3} \mathrm{O}_{4}-\mathrm{C}_{18}-$ Chitosan MNPs. The size and structure of $\mathrm{Fe}_{3} \mathrm{O}_{4}$ and $\mathrm{Fe}_{3} \mathrm{O}_{4}-\mathrm{C}_{18}$-chitosan MNPs were determined by $\mathrm{H}-7500$ transmission electronic microscopy (Hitachi, Tokyo, Japan) operating at $80 \mathrm{kV}$; the vibrating sample magnetization (VSM) curve of $\mathrm{Fe}_{3} \mathrm{O}_{4}-\mathrm{C}_{18}$-chitosan MNPs was analyzed by using an LDJ9600 vibrating sample magnetometer (LDJ Electronics, Troy, MI). The successes of functionalization of the octadecyl group and coating of chitosan-tripolyphosphate polymer were proved by the infrared (IR) spectra of naked $\mathrm{Fe}_{3} \mathrm{O}_{4}$ MNPs, $\mathrm{Fe}_{3} \mathrm{O}_{4}-\mathrm{C}_{18}$ MNPs, and $\mathrm{Fe}_{3} \mathrm{O}_{4}-\mathrm{C}_{18}$-chitosan MNPs, which were taken in $\mathrm{KBr}$ pressed pellets on a NEXUS 670 infrared Fourier transform spectrometer (Nicolet Thermo, Waltham, MA).

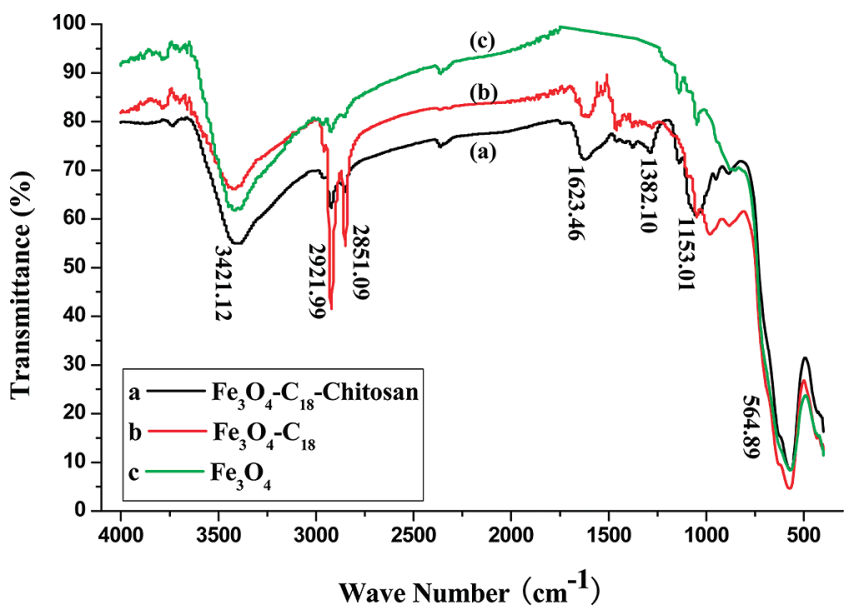

Figure 2. Infrared spectra of the $\mathrm{Fe}_{3} \mathrm{O}_{4}-\mathrm{C}_{18}$-chitosan MNPs (a), $\mathrm{Fe}_{3} \mathrm{O}_{4}-\mathrm{C}_{18}$ MNPs (b), and naked $\mathrm{Fe}_{3} \mathrm{O}_{4}$ MNPs (c).

Enrichment Procedure. The whole extraction procedure of the analytes from water samples with the $\mathrm{Fe}_{3} \mathrm{O}_{4}-\mathrm{C}_{18}$-chitosan MNPs is shown in Scheme 1b. First, $0.1 \mathrm{~g}$ of MNP adsorbent was dispersed in $500 \mathrm{~mL}$ of a filtered water sample by ultrasonic irradiation, and the $\mathrm{pH}$ was adjusted to about 3.0 with $1 \mathrm{~mol} \mathrm{~L}^{-1}$ $\mathrm{NaOH}$ or $\mathrm{HCl}$. Second, the MNPs were isolated from the suspension with a $\mathrm{Nd}-\mathrm{Fe}-\mathrm{B}$ strong magnet $(150 \mathrm{~mm} \times 100$ $\mathrm{mm} \times 20 \mathrm{~mm}$ ) after $20 \mathrm{~min}$ of adsorption. Next, the adsorbed analytes were eluted from the isolated adsorbent with $12 \mathrm{~mL}$ of methanol containing $0.28 \%$ aqueous ammonia ( $3 \mathrm{~mL}$ every time and washed four times). Then, the eluate (in a $15 \mathrm{~mL}$ polypropylene graduated conical bottom centrifuge tube, Corning Inc., Corning, NY) was concentrated with a stream of nitrogen at $55^{\circ} \mathrm{C}$ to less than $0.5 \mathrm{~mL}$ and diluted to $0.5 \mathrm{~mL}$ with methanol containing $0.28 \%$ aqueous ammonia. Finally, 10 $\mu \mathrm{L}$ of this solution was injected into the HPLC-MS/MS system for analysis.

Liquid Chromatography-Tandem Mass Spectrometry Analysis. Separation and quantification of PFCs were performed by using an HPLC-MS/MS system. The HPLC apparatus was a Dionex HPLC system (Sunnyvale, CA), composed of a P680 pump, an UltiMate 3000 autosampler, and Chromeleon 6.70 software. PFCs were separated on an Acclaim $120 \mathrm{C}_{18}$ column (5 $\mu \mathrm{m}$ particle diameter, $4.6 \mathrm{~mm}$ i.d. $\times 150 \mathrm{~mm}$ length, Dionex) with an aliquot of $10 \mu \mathrm{L}$ injection. Mass spectrometry was performed with a tandem mass spectrometer system (API 3200; Applied Biosystems/MDS SCIEX, Foster City, CA) with an electrospray ionization source (ESI-MS/MS) operated in electrospray negative ionization mode and Analyst 1.4.2 software. A $10 \mathrm{~min}$ dualistic gradient of $100 \%$ methanol (A) and $50 \mathrm{mmol} \mathrm{L}^{-1}$ $\mathrm{NH}_{4} \mathrm{OAc}$ (B) was employed. Generally, it began with $28 \%$ $\mathrm{NH}_{4} \mathrm{OAc}$, and $\mathrm{NH}_{4} \mathrm{OAc}$ was reduced to $5 \%$ at 4 min before being returned to the original condition at $7 \mathrm{~min}$. The flow rate was operated at $1.0 \mathrm{~mL} \mathrm{~min}{ }^{-1}$.

All the analysis and quantification were conducted using the ESI-MS/MS system. MS/MS parameters were optimized in multiselected reaction monitoring (MRM). The experimental conditions are shown in the Supporting Information (Table S1). Correlation between peak areas and analyte concentrations (0.5-50 ng L $\left.\mathrm{L}^{-1}\right)$ was determined by linear regression with a correlation coefficient in the range of $0.995-0.999$. 


\begin{tabular}{|c|c|c|c|c|c|c|c|}
\hline water sample & PFOA & PFOS & PFNA & PFDA & PFUnDA & PFDoDA & PFTA \\
\hline tap water & $93 \pm 3$ & $107 \pm 3$ & $93 \pm 5$ & $106 \pm 6$ & $102 \pm 4$ & $104 \pm 1$ & $102 \pm 2$ \\
\hline rainwater & $95 \pm 6$ & $103 \pm 1$ & $105 \pm 3$ & $95 \pm 1$ & $102 \pm 3$ & $93 \pm 4$ & $85 \pm 4$ \\
\hline Gaobeidian wastewater & $84 \pm 2$ & $86 \pm 2$ & $97 \pm 2$ & $85 \pm 1$ & $83 \pm 4$ & $82 \pm 4$ & $101 \pm 3$ \\
\hline $\begin{array}{l}\text { Xiaoqinghe River } \\
\text { water }\end{array}$ & $93 \pm 4$ & $89 \pm 3$ & $92 \pm 4$ & $87 \pm 1$ & $84 \pm 2$ & $80 \pm 1$ & $92 \pm 3$ \\
\hline
\end{tabular}

Following a similar enrichment and analysis procedure, optimization of the extraction of PFCs with $\mathrm{Fe}_{3} \mathrm{O}_{4}-\mathrm{C}_{18}-$ chitosan MNPs was conducted by extracting spiked ultrapure water (5 ng $\mathrm{L}^{-1}$ ) with $100 \mathrm{mg}$ of $\mathrm{Fe}_{3} \mathrm{O}_{4}-\mathrm{C}_{18}$-chitosan MNPs under a variety of experimental conditions, and the optimum conditions were established in terms of the recoveries of the target compounds.

Sample Collection and Analysis. Water samples were obtained from different districts of Beijing, China. Influent domestic wastewater samples were collected from the Gaobeidian wastewater treatment plant (Chaoyang district, Beijing). River water samples were collected from the Xiaoqinghe River (Haidian district, Beijing) in May 2009. The samples were taken at $10 \mathrm{~cm}$ below the water surface. Tap water samples were from our laboratory in the Haidian district, Beijing. Rainwater was collected in the garden of the Research Center for Eco-Environmental Sciences (Haidian district, Beijing) on May 10, 2009. The entire rain event was captured with a funnel-shaped, open homemade collector made of poly (vinyl chloride) (PVC) and then transferred into $1 \mathrm{~L}$ precleaned polypropylene containers. All the samples were stored in $1 \mathrm{~L}$ methanol-rinsed and air-dried polypropylene bottles with narrow mouths and screw tops and were filtered through $0.22 \mu \mathrm{m}$ nylon membranes to remove suspended solids. The filtered samples were stored at $4{ }^{\circ} \mathrm{C}$ until analysis. All the samples were analyzed within a week.

The potential contamination from the homemade collector, precleaned polypropylene bottles, and container used in the determination procedure were tested by running blank PFC-free water. None of the target analytes were detected in the blanks.

\section{RESULTS AND DISCUSSION}

Characterization of $\mathrm{Fe}_{3} \mathrm{O}_{4}-\mathrm{C}_{18}-$ Chitosan MNPs. The TEM images of $\mathrm{Fe}_{3} \mathrm{O}_{4}$ and $\mathrm{Fe}_{3} \mathrm{O}_{4}-\mathrm{C}_{18}$-chitosan MNPs are shown in Figure 1a. The naked $\mathrm{Fe}_{3} \mathrm{O}_{4}$ nanoparticles had a uniform size of about $15 \mathrm{~nm}$. After being functionalized with a $\mathrm{C}_{18}$ group and coated with chitosan polymer (Figure $1 \mathrm{~b}$ ), the $\mathrm{Fe}_{3} \mathrm{O}_{4}-\mathrm{C}_{18}-$ chitosan MNPs, with a diameter of about $20 \mathrm{~nm}$, had a typical core-shell structure and remained discrete in solution. The hydrophilic chitosan-tripolyphosphate polymer was coated on the core homogeneously.

The VSM curve of $\mathrm{Fe}_{3} \mathrm{O}_{4}-\mathrm{C}_{18}$-chitosan MNPs is shown in the Supporting Information (Figure S1). The MNPs had high saturation magnetization of $52.2 \mathrm{emu}^{-1}$, which made them susceptible to magnetic fields and easy to isolate from water solution. The hysteresis loops, with little hysteresis, remanence, and coercivity, illustrate the superparamagnetic characteristic of the MNPs, which is necessary for practical application.

The successful functionalization of the octadecyl group and coating of chitosan-tripolyphosphate polymer were proved by the IR spectra of naked $\mathrm{Fe}_{3} \mathrm{O}_{4} \mathrm{MNPs}, \mathrm{Fe}_{3} \mathrm{O}_{4}-\mathrm{C}_{18} \mathrm{MNPs}$, and
$\mathrm{Fe}_{3} \mathrm{O}_{4}-\mathrm{C}_{18}-$ chitosan MNPs (Figure 2). The peaks at $564 \mathrm{~cm}^{-1}$ observed in curves $\mathrm{a}-\mathrm{c}$ is related to the $\mathrm{Fe}-\mathrm{O}$ group, and the peak around $3420 \mathrm{~cm}^{-1}$ in curve a was assigned to the $-\mathrm{OH}$ group on the surface of magnetite. ${ }^{22}$ Characteristic bands of saturated $\mathrm{C}-\mathrm{H}$ absorption at 2851 and $2921 \mathrm{~cm}^{-1}$ and $\mathrm{O}-\mathrm{Si}-\mathrm{C}$ absorption at $1623 \mathrm{~cm}^{-1}$ in curves $\mathrm{b}$ and $\mathrm{c}$ demonstrated the successful modification with the octadecyl group, ${ }^{11}$ but these absorption bands in curve c were much lower because of the chitosan coating. The absorption bands appearing at $1382 \mathrm{~cm}^{-1}$ in curve c could be ascribed to $-\mathrm{C}-\mathrm{O}$ stretching of the primary alcoholic group in chitosan, and the presence of the $\mathrm{P}=\mathrm{O}$ groups in tripolyphosphate was indicated by the peak at 1153 $\mathrm{cm}^{-1} .25$ The broad band near $3300-3500 \mathrm{~cm}^{-1}$ was attributed to the stretching vibration of $\mathrm{O}-\mathrm{H}$, extension vibration of $\mathrm{N}-\mathrm{H}$, and inter-hydrogen bonds of the polysaccharide. ${ }^{25}$ These results indicated that chitosan-tripolyphosphate polymer was coated on the $\mathrm{Fe}_{3} \mathrm{O}_{4}-\mathrm{C}_{18}$ MNPs successfully.

Effect of the Solution pH. To examine the effect of the solution $\mathrm{pH}$, the $\mathrm{pH}$ was adjusted to designated values in the range of 3.0-10.0. The charge property of the $\mathrm{Fe}_{3} \mathrm{O}_{4}-\mathrm{C}_{18}-$ chitosan MNP surface, which varies with the solution $\mathrm{pH},{ }^{25}$ is a main factor affecting the adsorption of target compounds on the adsorbent. The $\zeta$ potential of $\mathrm{Fe}_{3} \mathrm{O}_{4}-\mathrm{C}_{18}-$ chitosan MNPs was determined in aqueous solutions in the $\mathrm{pH}$ range of 3.0-11.0. As shown in the Supporting Information (Figure S2), the isoelectric point (iep) of $\mathrm{Fe}_{3} \mathrm{O}_{4}-\mathrm{C}_{18}-$ chitosan MNPs was at about $\mathrm{pH}$ 6.9. Figure $\mathrm{S} 3 \mathrm{a}$ (Supporting Information) shows the adsorption of PFCs onto $\mathrm{Fe}_{3} \mathrm{O}_{4}-\mathrm{C}_{18}$ - chitosan MNPs at different $\mathrm{pH}$ values. At $\mathrm{pH}>8.0$, the chitosan-tripolyphosphate polymer coating of the MNPs was negatively charged, which resulted in the electrostatic repulsion between the adsorbent and the target molecules, so the recoveries of all analytes decreased at high solution $\mathrm{pH}$, but the influence was weakened with an increase of the carbon number of the molecules due to the enhanced hydrophobic property. In the $\mathrm{pH}$ range of 3.0-7.0, the chitosan polymer coating was positively charged, the analytes could be attracted by the interior hydrophobic layer of the adsorbent as well as the chitosan polymer coating, and the recoveries of all analytes approached $100 \%$.

To prove the contribution of chitosan polymer coating to extraction of PFCs, we synthesized $\mathrm{Fe}_{3} \mathrm{O}_{4}$-chitosan MNPs without a $\mathrm{C}_{18}$ layer and applied them to extract PFCs at different $\mathrm{pH}$ values (Figure S3b, Supporting Information). The results indicated that the chitosan coating was more attractive to longcarbon-chain PFCs due to their lower $\mathrm{p} K_{\mathrm{a}}{ }^{26}$ and a higher extraction efficiency was obtained at low $\mathrm{pH}$ because the chitosan coating was positively charged as the $\mathrm{pH}$ was below 6.0. At $\mathrm{pH} 9.0$, the recoveries of all analytes were extremely 


$\begin{array}{lccccc}\text { analyte } & \left.\text { linearity range }(\mathrm{ng} \mathrm{L})^{-1}\right) & \text { calibration equation } & r & \mathrm{RSD}(\%)(n=3) & \text { detection limit }^{a}\left(\mathrm{ng} \mathrm{L}^{-1}\right) \\ \text { PFOA } & 0.5-50 & y=5650 x+4.26 \mathrm{E}-5 & 0.9978 & 6.7 & 0.19 \\ \text { PFOS } & 0.5-50 & y=39900 x-1.32 \mathrm{E}-6 & 0.9972 & 8.1 & 0.036 \\ \text { PFNA } & 0.5-50 & y=7330 x+3.22 \mathrm{E}-9 & 0.9998 & 3.0 & 0.14 \\ \text { PFDA } & 0.5-50 & y=5150 x-1.62 \mathrm{E}-7 & 0.9981 & 9.4 & 0.051 \\ \text { PFUnDA } & 0.5-50 & y=4810 x-2.04 \mathrm{E}-7 & 0.9955 & 7.8 & 0.033 \\ \text { PFDoDA } & 0.5-50 & y=2390 x-6.05 \mathrm{E}-8 & 0.9986 & 8.3 & 0.052 \\ \text { PFTA } & 0.5-50 & y=3450 x-9.74 \mathrm{E}-8 & 0.9966 & 7.9 & 0.045\end{array}$

${ }^{a}$ The detection limits were calculated by using $\mathrm{S} / \mathrm{N}=3$.

Table 3. Mean Concentration \pm Standard Deviation $(n=3)$ of the PFCs Found in Water Samples, Recoveries \pm Standard Deviations $(n=3)$ Obtained upon Spiking with the Target Analytes, and Detection Limits (ng $\mathbf{L}^{-1}$ ) of Target Analytes in Different Matrixes

\begin{tabular}{|c|c|c|c|c|c|c|c|}
\hline & PFOA & PFOS & PFNA & PFDA & PFUnDA & PFDoDA & PFTA \\
\hline 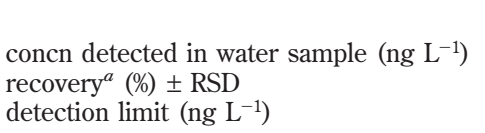 & $\begin{array}{l}\mathrm{nd}^{b} \\
88 \pm 3 \\
0.17\end{array}$ & $\begin{array}{l}\text { Tap } \\
\text { nd } \\
112 \pm 4 \\
0.049\end{array}$ & $\begin{array}{l}\text { ter } \\
\text { nd } \\
101 \pm 4 \\
0.12\end{array}$ & $\begin{array}{l}\text { nd } \\
107 \pm 3 \\
0.071\end{array}$ & $\begin{array}{l}\text { nd } \\
106 \pm 3 \\
0.047\end{array}$ & $\begin{array}{l}\text { nd } \\
106 \pm 4 \\
0.049\end{array}$ & $\begin{array}{l}\text { nd } \\
103 \pm 5 \\
0.055\end{array}$ \\
\hline $\begin{array}{l}\text { concn detected in water sample }\left(\mathrm{ng} \mathrm{L}^{-1}\right) \\
\text { recovery }(\%) \pm R S D \\
\text { detection limit }\left(\mathrm{ng} \mathrm{L} \mathrm{L}^{-1}\right)\end{array}$ & $\begin{array}{l}3.01 \pm 0.08 \\
108 \pm 8 \\
0.2\end{array}$ & $\begin{array}{l}\text { nd } \\
100 \pm 4 \\
0.076\end{array}$ & $\begin{array}{l}0.64 \pm 0.08 \\
109 \pm 8 \\
0.13\end{array}$ & $\begin{array}{l}\text { nd } \\
93 \pm 6 \\
0.093\end{array}$ & $\begin{array}{l}\text { nd } \\
84 \pm 7 \\
0.055\end{array}$ & $\begin{array}{l}\text { nd } \\
76 \pm 4 \\
0.11\end{array}$ & $\begin{array}{l}\text { nd } \\
66 \pm 5 \\
0.079\end{array}$ \\
\hline $\begin{array}{l}\text { concn detected in water sample }\left(n g \mathrm{~L}^{-1}\right) \\
\text { recovery }(\%) \pm R S D \\
\text { detection limit }\left(\mathrm{ng} \mathrm{L}^{-1}\right)\end{array}$ & $\begin{array}{l}8.33 \pm 0.06 \\
94 \pm 6 \\
0.24\end{array}$ & $\begin{array}{l}\text { Gaobeidian } \\
3.22 \pm 0.02 \\
63 \pm 2 \\
0.093\end{array}$ & $\begin{array}{l}\text { astewater } \\
2.05 \pm 0.05 \\
84 \pm 5 \\
0.24\end{array}$ & $\begin{array}{l}1.89 \pm 0.02 \\
56 \pm 2 \\
0.14\end{array}$ & $\begin{array}{l}\text { nd } \\
66 \pm 8 \\
0.075\end{array}$ & $\begin{array}{l}\text { nd } \\
56 \pm 5 \\
0.24\end{array}$ & $\begin{array}{l}\text { nd } \\
72 \pm 5 \\
0.17\end{array}$ \\
\hline $\begin{array}{l}\text { concn detected in water sample }\left(\mathrm{ng} \mathrm{L}^{-1}\right) \\
\text { recovery }(\%) \pm R S D \\
\text { detection limit }\left(\mathrm{ng} \mathrm{L}^{-1}\right)\end{array}$ & $\begin{array}{l}32.4 \pm 0.08 \\
90 \pm 8 \\
0.24\end{array}$ & $\begin{array}{l}\text { Xiaoqinghe } \\
0.962 \pm 0.06 \\
65 \pm 6 \\
0.12\end{array}$ & $\begin{array}{l}\text { yer Water } \\
0.958 \pm 0.07 \\
79 \pm 7 \\
0.23\end{array}$ & $\begin{array}{l}0.760 \pm 0.07 \\
62 \pm 7 \\
0.08\end{array}$ & $\begin{array}{l}\text { nd } \\
75 \pm 6 \\
0.091\end{array}$ & $\begin{array}{l}\text { nd } \\
69 \pm 4 \\
0.14\end{array}$ & $\begin{array}{l}\text { nd } \\
72 \pm 2 \\
0.092\end{array}$ \\
\hline
\end{tabular}

low, caused by the electrostatic repulsion between the adsorbent and the target molecules.

According to these results, it can be inferred that the $\mathrm{C}_{18}$ layer is mainly responsible for the adsorption of PFCs to $\mathrm{Fe}_{3} \mathrm{O}_{4}-\mathrm{C}_{18}-$ chitosan MNP adsorbent. At the same time, the chitosan polymer coating also plays a role at low $\mathrm{pH}$, which is especially important to short-carbon-chain PFCs because their interaction with the $\mathrm{C}_{18}$ layer is rather weak.

Effect of Humic Acid at Different pH Values. Humic acid is the most common NOM in an environmental water sample and may adsorb many organic compounds due to the skeleton of alkyl and aromatic units attached with carboxylic acid, phenolic hydroxyl, and quinone functional groups. ${ }^{3}$ It can also adhere onto and contaminate the adsorbent. Parts $a$ and $b$ of Figure S4 (Supporting Information) show the effects of humic acid on the adsorption of PFCs on $\mathrm{Fe}_{3} \mathrm{O}_{4}-\mathrm{C}_{18}$-chitosan MNPs at $\mathrm{pH} 3.0$ and 7.0, respectively. With the addition of humic acid in the range of $0-100 \mathrm{mg} \mathrm{L}^{-1}$, recoveries of all analytes decreased gradually with an increase of the humic acid concentration, and the influence on long-carbon-chain PFCs was relatively small because of their high affinity to adsorbent. Low $\mathrm{pH}$ was found to be favorable for the adsorption of PFCs on adsorbent. When the concentration of humic acid was $50 \mathrm{mg} \mathrm{L}^{-1}$ (a rather high concentration in an environmental water sample), the recoveries of all analytes were higher than $75 \%$ at $\mathrm{pH} 3.0$. Therefore, $\mathrm{Fe}_{3} \mathrm{O}_{4}-\mathrm{C}_{18}-$ chitosan MNP adsorbent might be used to quantitatively extract PFCs from water samples with a high concentration of humic acid at $\mathrm{pH}$ 3.0. However, at $\mathrm{pH} 7.0$, the recoveries of PFOA, PFOS, and PFNA were not higher than $50 \%$ (Figure $\mathrm{S} 4 \mathrm{~b}$ ), even when the concentration of humic acid was as low as $10 \mathrm{mg} \mathrm{L}^{-1}$. This is probably due to the fact that the affinity of the adsorbent to PFCs is higher at lower $\mathrm{pH}$ due to the electrostatic force of the chitosan coating. Furthermore, humic acid tends to aggregate at lower $\mathrm{pH}$ to form larger granules $^{30}$ and is prevented from contaminating the $\mathrm{C}_{18}$ layer by size exclusion of the porous chitosan coating, which improves the anti-interference ability of $\mathrm{Fe}_{3} \mathrm{O}_{4}-\mathrm{C}_{18}-$ chitosan MNP adsorbent.

Influence of Protein at Different pH Values. Protein, arising from the cell debris of microbes, plants, or animals, is another common NOM in environmental water samples, ${ }^{31}$ especially in a eutrophicated water body and municipal sewage. It can also influence the adsorption of target molecules on the adsorbent. Parts $\mathrm{a}$ and $\mathrm{b}$ of Figure S5 (Supporting Information) show the effects of protein on the extraction of PFCs at $\mathrm{pH} 3.0$ and 7.0, respectively. With the addition of BSA in the range of $0.0-1.0 \mathrm{~g}$ $\mathrm{L}^{-1}$, recoveries of all analytes decreased gradually with the concentration of BSA. The influence of BSA on PFC extraction was smaller at $\mathrm{pH} 3.0$ than $\mathrm{pH}$ 7.0. When the concentration of BSA was $0.2 \mathrm{~g} \mathrm{~L}^{-1}$, the recoveries of all analytes were higher than $60 \%$ at pH 3.0, but less than $30 \%$ at $\mathrm{pH} 7.0$, except for PFTA (50\%). Both BSA and chitosan polymer were positively charged

(30) Coles, C. A.; Yong, R. N. Eng. Geol. 2006, 85, 26-32.

(31) Zhang, M. L.; Sheng, G. P.; Yu, H. Q. Water Res. 2008, 42, 3464-3472. 


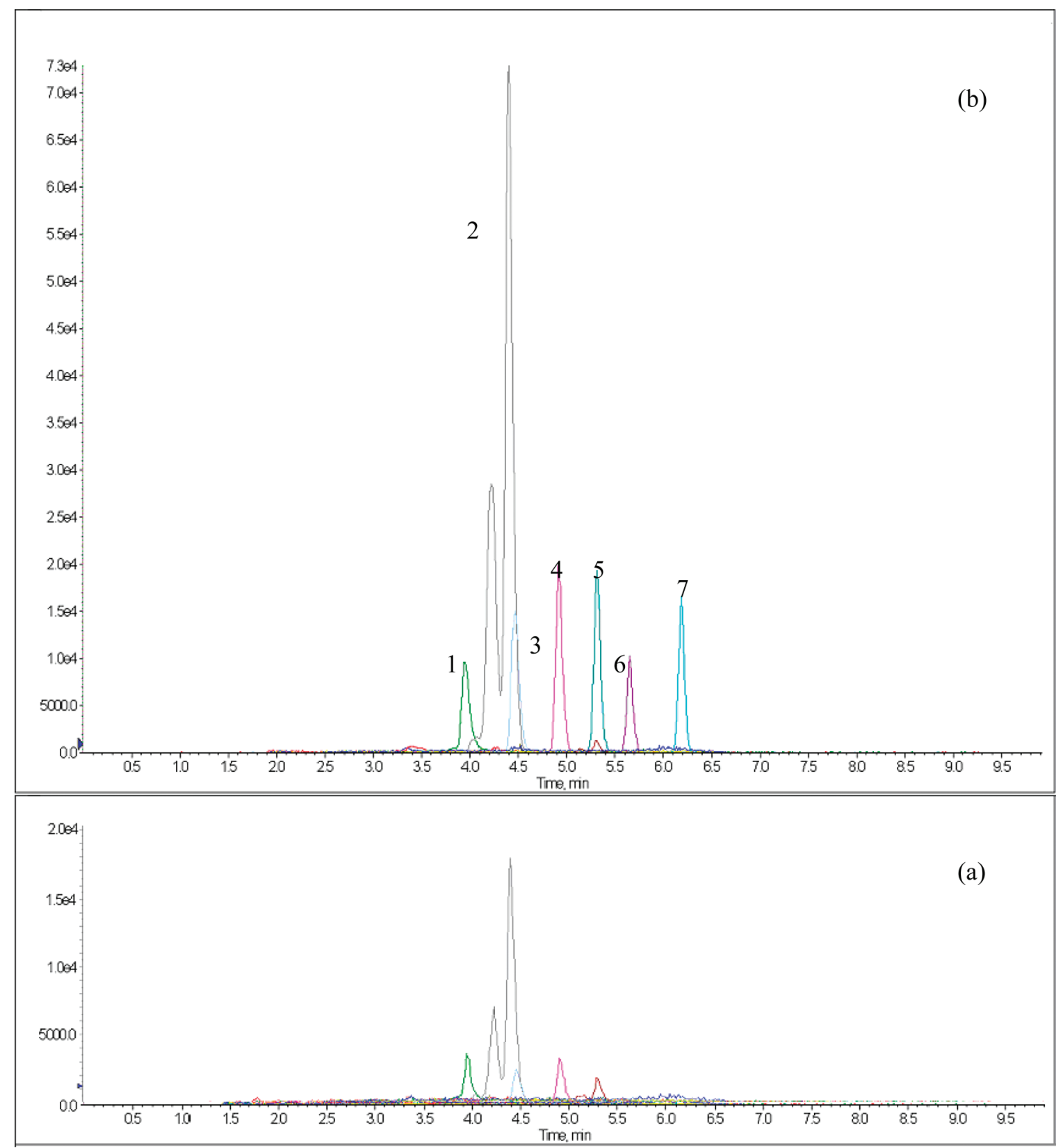

Figure 3. LC-ESI-MS/MS chromatograms of a Gaobeidian wastewater sample extracted by $\mathrm{Fe}_{3} \mathrm{O}_{4}-\mathrm{C}_{18}-$ chitosan MNP adsorbent: (a) Gaobeidian wastewater sample; (b) Gaobeidian wastewater sample spiked with a $10 \mathrm{ng} \mathrm{L}^{-1}$ concentration of each compound (1, PFOA; 2 , PFOS; 3, PFNA; 4, PFDA, 5, PFUnDA, 6, PFDoDA, 7, PFTA).

at $\mathrm{pH}$ 3.0. Then the repulsive interaction between them hindered the adsorption of BSA onto the adsorbent, which was beneficial to the extraction of targets. On the other hand, there was probably existing competitive adsorption of BSA and adsorbent to negatively charged PFCs, and the recoveries of PFCs with a short carbon chain decreased more obviously due to their weak affinity to the adsorbent. At pH 7.0, BSA might adhere onto the surface of the adsorbent and block the pores of chitosan polymer, which was the possible reason for the significant decrease of analyte recoveries.

The above results show that $\mathrm{Fe}_{3} \mathrm{O}_{4}-\mathrm{C}_{18}$-chitosan MNP adsorbent has a higher anti-interference ability for humic acid and protein at $\mathrm{pH} 3.0$ than $\mathrm{pH}$ 7.0. Therefore, $\mathrm{pH} 3.0$ was selected as the desired condition for the enrichment of PFCs from water samples with complex matrixes.
Effect of the Solution Volume. The effect of the sample volume on the recoveries of the analytes was examined by preconcentrating different volumes $(200-1000 \mathrm{~mL})$ of distilled water spiked with $2.5 \mathrm{ng}$ of each analyte. The result is shown in the Supporting Information (Figure S6). Under the optimal

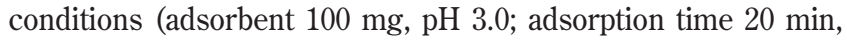
eluent $12 \mathrm{~mL}$ of methanol containing $0.28 \%$ ammonia), the recoveries of all analytes were still above $90 \%$ with a sample volume up to $500 \mathrm{~mL}$, indicating the high adsorption ability of the $\mathrm{Fe}_{3} \mathrm{O}_{4}-\mathrm{C}_{18}$-chitosan MNP adsorbent. By concentrating the eluates to $0.5 \mathrm{~mL}$ with a nitrogen flow, concentration factors of 1000 were easily achieved.

The matrix effect of different kinds of environmental water samples on the extraction efficiencies of PFCs was investigated by extracting $500 \mathrm{~mL}$ of different environmental water samples 
spiked with $10.0 \mathrm{ng}$ of each analyte. The extraction efficiencies of PFCs in wastewater and river samples were slightly lower than those obtained from tap water and rainwater samples (shown in Table 1). However, even for samples with a complex matrix, the extraction efficiencies of PFCs were still higher than $80 \%$, so we concluded that the matrix only had a slight influence on the extraction of PFCs.

Effect of the Adsorption Time. The effect of the adsorption time on the extraction of target compounds was studied with distilled water spiked with various analytes $\left(5 \mathrm{n} \mathrm{L} \mathrm{L}^{-1}\right)$, and the adsorption time varied from 0.0 to $90 \mathrm{~min}$. As can been seen from Figure S7 (Supporting Information), 20 min was sufficient to reach adsorption equilibrium, which could meet the need of rapid analysis, and the recoveries of all analytes were above $90 \%$. Therefore, $20 \mathrm{~min}$ was chosen as the adsorption time for further studies.

Desorption Conditions. Different solvents including acetonitrile, methanol, and methanol containing $0.28 \%$ aqueous ammonia with different volumes $(3.0-12.0 \mathrm{~mL})$ were used to elute the analytes from $\mathrm{Fe}_{3} \mathrm{O}_{4}-\mathrm{C}_{18}-$ chitosan MNPs. The desorption ability of methanol containing $0.28 \%$ aqueous ammonia was found to be superior to that of methanol and acetonitrile. Almost all analytes were quantitatively eluted from adsorbent by using $12 \mathrm{~mL}$ of methanol containing $0.28 \%$ ammonia ( $3 \mathrm{~mL}$ every time and washed four times), which was selected for the elution of the analytes from the adsorbents.

Analytical Performance. Calibration curves were run for the determination of PFCs by using $500 \mathrm{~mL}$ of distilled water spiked with various analytes in the range of $0.5-50 \mathrm{ng} \mathrm{L}^{-1}$. According to the above-mentioned optimal conditions, the calibration curves were established and quantitative parameters such as the linear range, correlation coefficient, and detection limit were evaluated. The results are shown in Table 2. The correlation coefficients $(r)$ of the calibration curves are $0.9978,0.9972,0.9998,0.9981,0.9955,0.9986$, and $0.9966(n=7)$, with detection limits of $0.19,0.036,0.14,0.051$, 0.033, 0.052, and $0.045 \mathrm{ng} \mathrm{L}^{-1}$ for PFOA, PFOS, PFNA, PFDA, PFUnDA, PFDoDA, and PFTA, respectively (calculated by using $\mathrm{S} / \mathrm{N}=3$ ).

Analysis of Environmental Water Samples. According to the established method, the concentrations of PFCs in some real water samples were measured. The concentrations and recoveries obtained for the analytes, expressed as the mean value $(n=3)$, are listed in Table 3 . Among the water samples, no PFCs were detected in rainwater and tap water. PFDoDA, PFUnDA, and PFTA were not found in all water samples. Low concentrations of PFOS, PFNA, PFDA, and PFOA were found in Gaobeidian wastewater and Xiaoqing River water samples. The concentration of PFOA was relatively higher than those of the other PFCs, especially in the Xiaoginghe River. Recoveries of PFOA, PFOS, PFNA, PFDA, PFUnDA, PFDoDA, and PFTA were in the ranges of $88-108 \%, 63-112 \%, 79-109 \%$, $56-107 \%, 66-106 \%, 56-106 \%$, and $66-103 \%$ for the four water samples, with a low relative standard deviation of the determinations ranging from $2 \%$ to $8 \%$. The HPLC-ESI-MS/MS chromatograms of the Gaobeidian wastewater sample and its spiked solution are shown in Figure 3.
Commercial RP-C ${ }_{18},{ }^{32,33}$ Water Oasis HLB, ${ }^{34,35}$ or WAX ${ }^{36,37}$ SPE cartridges have been used to extract PFCs from environmental water samples by many groups. The LODs and recoveries obtained with $\mathrm{C}_{18}$, HLB, or WAX cartridges are listed in Table $\mathrm{S} 2$ in the Supporting Information. Compared with these results, the LOD of the proposed method in this research was increased by $10-50$-fold relative to that obtained with the $\mathrm{RP}^{-} \mathrm{C}_{18}$ cartridge, and was similar to those of HLB and WAX cartridges. However, the preconcentration procedure was simplified greatly, and plenty of time was saved. Only $40 \mathrm{~min}$ was required with the proposed method and MNP adsorbents to pretreat $500 \mathrm{~mL}$ water samples, while at least $3 \mathrm{~h}$ was demanded with conventional SPE cartridges. Therefore, we conclude that the $\mathrm{Fe}_{3} \mathrm{O}_{4}-\mathrm{C}_{18}-$ chitosan MNP sorbent is suited for the preconcentration of trace PFCs from large-volume environmental water samples with a complex matrix and the proposed method is reliable.

\section{CONCLUSIONS}

In this work, $\mathrm{Fe}_{3} \mathrm{O}_{4}-\mathrm{C}_{18}-$ chitosan MNP adsorbent was synthesized and applied to extract trace PFCs in some environmental water samples. The adsorbent, with a large surface area because of the nanometer size, could be isolated from the matrix solution easily due to the superparamagnetic $\mathrm{Fe}_{3} \mathrm{O}_{4}$ core. The hydrophobic $\mathrm{C}_{18}$ group of the interior layer provides a high extraction efficiency of the adsorbent to target compounds. The porous hydrophilic chitosan polymer coating has three functions: (i) it contributes to the adsorption of PFCs at low pH; (ii) it improves the dispersibility of the MNPs in water samples; (iii) most importantly, it allows analyte molecules to pass through and enter the interior layer of the adsorbent, while it prevents the NOM macromolecule from passing through the coating by the size exclusion effect and electrostatic repulsion as shown in Scheme 1a and thus enhances the anti-interference ability of the adsorbent. PFCs were extracted quantitatively from large-volume water samples with complex matrixes using this MNP adsorbent at $\mathrm{pH}$ 3. After being eluted from the adsorbent with a small volume of organic solvent and further concentration, the analytes were determined with subsequent HPLC-ESI-MS/MS analysis, and this method was proved to be viable. The advantages of this new MNP adsorbent include high anti-interference, high extraction efficiencies, and convenient operation.

\section{ACKNOWLEDGMENT}

This work was jointly supported by the High-Technology Research and Development Program of China (Grants 2007AA06A407 and 2007AA06Z405), The National Basic Research Program (Grant

(32) Risha, K.; Flaherty, J.; Wille, R.; Buck, W.; Morandi, F.; Isemura, T. Anal. Chem. 2005, 77, 1503-1508.

(33) Tseng, C. L.; Liu, L. L.; Chen, C. M.; Ding, W. H. J. Chromatogr., A 2006, 1105, 119-126.

(34) Loos, R.; Locoro, G.; Huber, T.; Wollgast, J.; Christoph, E. H.; Jager, A.; Gawlik, B. M.; Hanke, G.; Umlauf, G.; Zaldívar, J. M. Chemosphere 2008, $71,306-313$.

(35) Loganathan, B. G.; Sajwan, K. S.; Sinclair, E.; Kumar, K, S.; Kannan, K. Water Res. 2007, 41, 4611-4620.

(36) Yeung, L. W. Y.; Yamashita, N.; Taniyasu, S.; Lam, P. K. S.; Sinha, R. K.; Borole, D. V.; Kannan, K. Chemosphere 2009, 76, 55-62.

(37) Miyake, Y.; Yamashita, N.; Rostkowski, P.; So, M. K.; Taniyasu, S.; Lam, P. K. S.; Kannan, K. J. Chromatogr., A 2007, 1143, 98-104. 
2009CB421605), the Major Research Program of the Chinese Academy of Sciences (Grant KZCX2-YW-420-1), and the National Natural Science Foundation of China (Grants 20877079, 20837003, and 20890111).

\section{SUPPORTING INFORMATION AVAILABLE}

Experimental conditions of electrospray tandem mass spectrometry., comparison of analytical performances of the proposed method with those in other literature, VSM magnetization curves of $\mathrm{Fe}_{3} \mathrm{O}_{4}-\mathrm{C}_{18}$-chitosan MNPs, $\zeta$ potential of $\mathrm{Fe}_{3} \mathrm{O}_{4}-\mathrm{C}_{18}-$ chitosan MNPs, effect of $\mathrm{pH}$ on the adsorption of PFCs onto $\mathrm{Fe}_{3} \mathrm{O}_{4}-\mathrm{C}_{18}$-chitosan MNPs and $\mathrm{Fe}_{3} \mathrm{O}_{4}$-chitosan MNPs, effect of the concentration of humic acid on the recoveries of PFCs extracted by $\mathrm{Fe}_{3} \mathrm{O}_{4}-\mathrm{C}_{18}-$ chitosan MNP adsorbent at $\mathrm{pH} 3.0$ and 7.0, effect of the concentration of bovine serum albumin on the recoveries of PFCs extracted by $\mathrm{Fe}_{3} \mathrm{O}_{4}-\mathrm{C}_{18}$-chitosan MNP adsorbent at $\mathrm{pH} 3.0$ and 7.0, and effects of the adsorption time and loading volume on the recoveries of the analytes. This material is available free of charge via the Internet at http://pubs.acs.org.

Received for review November 11, 2009. Accepted February 4, 2010.

AC902589T 